\title{
LA-UR-13-26044
}

Approved for public release; distribution is unlimited.

Title: $\quad$ Biota Dose Assessment at LANL for 2012

Author(s): $\quad$ McNaughton, Michael

Brock, Burgandy

Intended for: Report

Issued: 2013-07-31

Disclaimer:

Los Alamos National Laboratory, an affirmative action/equal opportunity employer,is operated by the Los Alamos National

Security, LLC for the National NuclearSecurity Administration of the U.S. Department of Energy under contract DE-AC52-06NA25396. By approving this article, the publisher recognizes that the U.S. Government retains nonexclusive, royalty-free license to publish or reproduce the published form of this contribution, or to allow others to do so, for U.S. Government purposes.

Los Alamos National Laboratory requests that the publisher identify this article as work performed under the auspices of the

U.S. Departmentof Energy. Los Alamos National Laboratory strongly supports academic freedom and a researcher's right to publish; as an institution, however, the Laboratory does not endorse the viewpoint of a publication or guarantee its technical correctness. 


\section{Biota Dose Assessment at LANL for 2012}

Michael W. McNaughton and Burgandy R. Brock

Los Alamos National Laboratory

\section{Introduction}

As required by DOE Order 458.1, and as described in LANL 2009a and LANL 2009b, we use DOE-STD1153-2002 (DOE 2002) and RESRAD-Biota to demonstrate compliance with the DOE dose limits for biota. The first comprehensive biota-dose assessment was described in McNaughton 2005. This assessment concluded that there were no locations near Los Alamos where the DOE biota dose limits were exceeded. Annually, we consider new measurements and update the biota dose assessment as needed. During 2012, the most significant changes resulted from storm-water runoff, as expected during the first few years after the Las Conchas fire.

\section{Overview}

Beginning with the Manhattan Project, the earliest work with radioactive material was located in what is now the center of Los Alamos townsite, and some of those materials were released into the environment or disposed of as waste. These radioactive materials have been extensively studied and assessed in many reports during the past 60 years. The assessments consider many activities relevant to dose assessment, such as adventurous children who burrow into and eat the soil, as well as the activities of pets and wildlife. Even for the most extreme scenarios, the doses are less than a few mrem per year, well below the DOE limit for the public, and four orders of magnitude below the DOE limit to terrestrial animals, which is 0.1 rad per day.

Locations that pose even a very small risk to humans or pets are fenced, locked, and posted as controlled areas. However, it is recognized that biota such as plants, birds, mice, and earthworms live in these controlled areas. The DOE standard is intended to protect these biota.

Contaminated sites in and near Los Alamos consist of areas known as solid waste management units (SWMU) and areas of concern (AoC) that have been identified and studied extensively in many reports. LA-UR-90-4300 lists these locations, and many subsequent reports provide extensive details and assessments as referenced in the Annual Site Environmental Reports (LANL 2012.) Between these areas, the levels of detectable radioactive materials are many orders of magnitude smaller. Because they are not a focus of concern, the areas outside of SWMUs and AoCs have not been as extensively studied or sampled.

The highest concentrations of radioactive materials resulting from historic LANL operations are buried in material disposal areas (MDAs) such as MDA A, C, G, T, etc. Much of this material is sealed in containers that are not accessible to biota (McNaughton 2005). In some cases, it is buried below the reach of tree roots or burrowing animals, and in some cases it is encased or embedded in concrete.

Of particular relevance to the present report, the hills to the west of LANL, where the Las Conchas fire burned, are not contaminated with LANL-derived substances. The radioactivity in these hills consists of naturally occurring radioactive material (NORM) and global fallout. 


\section{Background}

According to DOE-STD-1153-2002 (DOE 2002), "background levels may be taken into account when determining compliance of DOE activities with the biota dose limits." DOE 2002 continues "For example, this may be a consideration for the two isotopes of radium" (Module 1 Section 6.1.2.)

Natural uranium and its decay products such as radium are distinguished from the uranium used at LANL by methods such as process knowledge, isotopic analysis, and by the presence of $\mathrm{Pb}-214$ and $\mathrm{Bi}-214$ in natural uranium. $\mathrm{Pb}-214$ and $\mathrm{Bi}-214$ have been removed from uranium used at LANL during the refinement process. These radionuclides, together with their parents, Th-230 and Ra-226, remain with the mill tailings at the mill, for example near Grand Junction, Colorado. The Pb-214 and Bi-214 decay products grow in with a half-life of 75,000 years so they are undetectable in the refined uranium used at many DOE sites.

In storm water, global-fallout radionuclides are likely to have higher concentrations than average for the following reasons.

- Fallout was deposited on the surface and usually remains near the surface, so it is preferentially swept into storm water.

- Fallout is mostly brought to earth by rain and snow fall, which are often higher than the regional average in the foothills west of LANL.

- Fallout often washes off rocky or impermeable slopes and accumulates in low-lying areas and in the path of storm-water runoff.

- Concentrations in ash are especially high because most fallout materials are refractory.

Global fallout may be distinguished from local contamination by methods such as process knowledge, isotopic analysis, and by the ratios of radionuclides, especially Pu-239,40, Am-241, and Cs-137.

\section{Pre-screening}

Each year, there are about 100,000 new measurements at about 1,000 locations, as listed in Table 1-2 of the Annual Site Environmental Reports (LANL 2012.) It is impractical to run RESRAD-Biota for every location, so we begin with pre-screening, as described in the Environmental Reports, to select locations that could approach the DOE limits.

Most of the results reported in the 2012 Environmental Report are similar to previous years and are far below screening levels. As reported in Chapter 6, the most significant change was in storm water and resulted from the Las Conchas fire.

\section{Las Conchas Fire}

The Las Conchas fire is discussed in the 2011 Environmental Report and additional reports referenced therein. Briefly, it burned during late June and early July 2011, immediately before the seasonal rainstorms that began in July. The burned areas on LANL included a one-to-two-acre area along the southern edge of technical area TA-49, and the area to the west of State Road 501, which runs close to the western boundary of LANL. No areas containing SWMUs or AoCs burned. 
The ash from any fire contains concentrated, naturally-occurring radioactive material (NORM) such as potassium-40, uranium, thorium, and their decay products. It also contains concentrated radioactive material from global fallout: americium, plutonium, cesium-137, and strontium-90. Near Los Alamos, the concentrations of potassium-40, uranium, and thorium are higher than the regional average because of the geology of the region (McNaughton 2008.) Near the mountains, the concentrations of global fallout are higher than the regional average because fallout is brought to earth by "wet-deposition," by rain and snowfall. In the hills where the fire burned, rain and snowfall are higher than the regional average. Most of the fallout remains near the surface, for example on forest litter, and is further concentrated in the ash that remains after the fire. Many of the radioactive elements are refractory, which means they remain with the ash, though there could be some fractionation in very high temperature fires. Thus, the concentrations in the ash are much higher than the regional averages in soils.

\section{Storm Water}

After a fire, surface vegetation is replaced by ash so the material on the surface is easily mobilized during a rain storm. Consequently, the storm-water runoff from burned areas is laden with sediment and ash. Furthermore, in burned areas the surface soil is relatively impermeable, which results in increased storm-water runoff. Following the Las Conchas fire, the concentrations of radioactive materials in unfiltered storm-water samples at some locations exceeded LANL screening levels for a short time, typically less than an hour.

Most of these locations are not aquatic or riparian habitats because the flow is ephemeral. For these locations, we consider the potential for doses to terrestrial plants and animals. Even locations with perennial flow do not support a typical riparian habitat because there is almost no aquatic life for a riparian animal to eat. For example, there are no fish in any of the streams that flow through LANL. Thus, many of the generic bioaccumulation factors in DOE 2002 and RESRAD-Biota do not apply at Los Alamos. Site-representative factors are discussed in McNaughton et al. 2008a.

The aquatic life that does exist at some locations consists mostly of insect larvae. In this case there is not enough biota mass to measure the concentration ratios and deduce site-specific bioaccumulation factors, so we rely on models. Large bioaccumulation factors typically occur where there is a complex food chain, and they depend on the availability of essential nutrients. For example, cesium bioaccumulates in locations that are deficient in potassium, and strontium or radium bio-accumulate in locations that are deficient in calcium. In contrast, the LANL environment is rich in potassium and calcium (McNaughton 2008b.) Cesium and strontium have been studied in the LANL environment (Salazar 2006) though radium has not.

\section{Water Canyon}

Consider the data for the storm water at Water Canyon near State Road 501 (E252.) Following a rainstorm on August 16, 2012, the suspended sediment concentration was high: $71 \mathrm{~g} / \mathrm{L}$. With this high sediment load, the analytical laboratory had difficulty obtaining a homogeneous mixture, extracting uniform aliquots, and dissolving all of the sediment, so the data are limited. The isotopic results indicate naturally occurring uranium, together with strontium-90 from global fallout in ash. The natural uranium concentration is $(172 \mathrm{pCi} / \mathrm{L}) \div(71 \mathrm{~g} / \mathrm{L})=2.4 \mathrm{pCi} / \mathrm{g}$, typical of uranium in soil or sediment near Los Alamos. The strontium-90 concentration is $(2.39 \mathrm{pCi} / \mathrm{L}) \div(71 \mathrm{~g} / \mathrm{L})=0.03 \mathrm{pCi} / \mathrm{g}$, which is less than the typical concentrations of global fallout near the surface, probably because the surface had been washed away by a previous storm, perhaps in 2011. 
We begin by running RESRAD-Biota with the available data. The RESRAD-Biota "Aquatic BCG Report for Level 1" (Table 1) lists a "Sum of Total Ratio" equal to 1.6. If these conditions are extended over a 24hour period, this would indicate an acute dose rate of 1.6 rad per day. This "Sum of Total Ratio" triggered a level-2 assessment. For the Level- 2 assessment, we replaced the default bioaccumulation factor for Sr-90, $320 \mathrm{pCi} / \mathrm{L}$, with the site-specific value obtained from McNaughton 2008a, LA-UR-082783: 30,000 pCi/L. The results did not change significantly because the $\mathrm{Sr}-90$ concentration, $2.39 \mathrm{pCi} / \mathrm{L}$, is much smaller than either the default or the site-specific BCG. So we proceeded to Level 3 of RESRADBiota.

For Level 3 of RESRAD-Biota we calculated the time-average values. The storm lasted less than an hour, storm-water runoff was present for much less than $0.1 \%$ of the time, and the base flow concentrations were much less than $0.1 \%$ of the storm-water concentrations, so the time-averaged concentrations were less than $0.1 \%$ of the maximum values listed in Table 1 . Therefore, the time-averaged chronic dose rate was less than $0.1 \%$ of the acute dose rate, i.e., less than $1.6 \times 10^{-3}$ rad per day.

The uranium was natural, so natural radium-226 was in secular equilibrium. Radium-226 was not measured so we deduced that the concentration was equal to that of the uranium. Table 2 uses timeaveraged concentrations that are $0.1 \%$ of the acute concentrations. The average dose rates are 0.018 $\mathrm{rad} /$ day for aquatic animals and $0.004 \mathrm{rad} /$ day for riparian animals, which are less than the DOE limits. 


\section{Aquatic BCG Report for Level 1}

Title: Water Canyon near S.R. 501, Aug 16, 2012

Sum of Total Ratio: 1.61E+00

Sum of Water Ratio: $1.60 \mathrm{E}+00$

Sum of Sediment Ratio: 5.09E-03

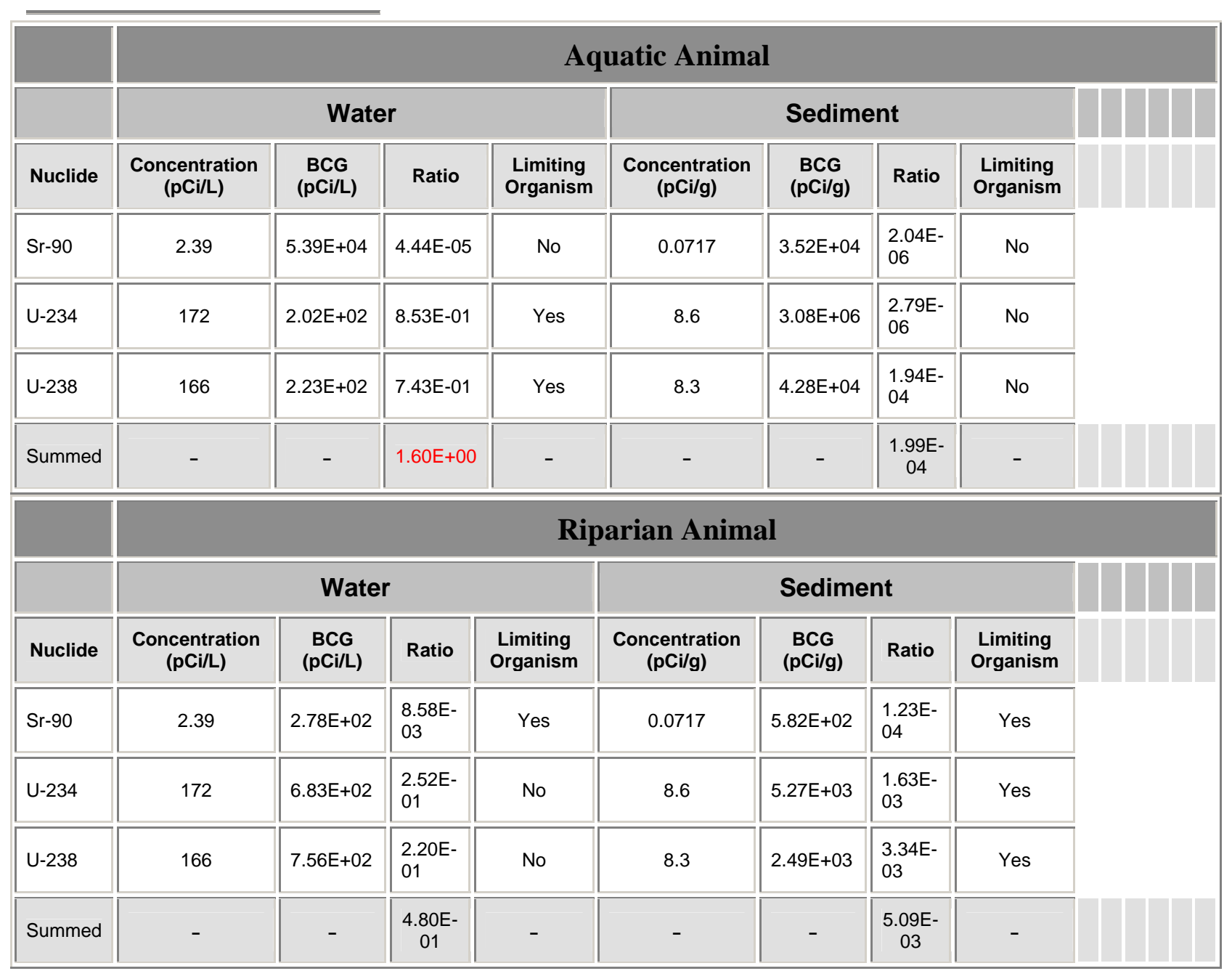

Table 1. Aquatic BCG Report for RESRAD-Biota Level 1, at Water Canyon near State Road 501, on August 16,2012 


\section{Dose Report for Level 3 in rad/d}

Title: Mean for Water Canyon near S.R. 501, Aug 16, 2012

\begin{tabular}{|c|c|c|c|c|c|}
\hline \multicolumn{6}{|c|}{ Aquatic Animal } \\
\hline Nuclide & Water & Soil & Sediment & Tissue & Summed \\
\hline Ra-226 & $\begin{array}{c}1.69 \mathrm{E}- \\
02\end{array}$ & $0.00 \mathrm{E}+00$ & $8.54 \mathrm{E}-07$ & $0.00 \mathrm{E}+00$ & 1.69E-02 \\
\hline Sr-90 & $\begin{array}{c}4.15 \mathrm{E}- \\
06\end{array}$ & $0.00 \mathrm{E}+00$ & 2.08E-09 & $0.00 \mathrm{E}+00$ & 4.15E-06 \\
\hline U-234 & $\begin{array}{c}8.52 \mathrm{E}- \\
04\end{array}$ & $0.00 \mathrm{E}+00$ & 2.84E-09 & $0.00 \mathrm{E}+00$ & 8.52E-04 \\
\hline U-238 & $\begin{array}{c}7.43 \mathrm{E}- \\
04\end{array}$ & $0.00 \mathrm{E}+00$ & 1.94E-07 & $0.00 \mathrm{E}+00$ & 7.43E-04 \\
\hline Summed & $\begin{array}{c}1.85 \mathrm{E}- \\
02\end{array}$ & $0.00 \mathrm{E}+00$ & 1.05E-06 & $0.00 \mathrm{E}+00$ & $1.85 \mathrm{E}-02$ \\
\hline \multicolumn{6}{|c|}{ Riparian Animal } \\
\hline Nuclide & Water & Soil & Sediment & Tissue & Summed \\
\hline Ra-226 & $\begin{array}{c}4.22 \mathrm{E}- \\
03\end{array}$ & $0.00 \mathrm{E}+00$ & 1.19E-05 & $0.00 \mathrm{E}+00$ & 4.23E-03 \\
\hline Sr-90 & $\begin{array}{c}8.57 \mathrm{E}- \\
07\end{array}$ & $0.00 \mathrm{E}+00$ & $1.23 \mathrm{E}-08$ & $0.00 \mathrm{E}+00$ & $8.70 \mathrm{E}-07$ \\
\hline $\mathrm{U}-234$ & $\begin{array}{c}2.52 \mathrm{E}- \\
05\end{array}$ & $0.00 \mathrm{E}+00$ & 1.63E-07 & $0.00 \mathrm{E}+00$ & 2.53E-05 \\
\hline U-238 & $\begin{array}{l}2.19 \mathrm{E}- \\
05\end{array}$ & $0.00 \mathrm{E}+00$ & 3.33E-07 & $0.00 \mathrm{E}+00$ & 2.23E-05 \\
\hline Summed & $\begin{array}{c}4.26 \mathrm{E}- \\
03\end{array}$ & $0.00 \mathrm{E}+00$ & $1.24 \mathrm{E}-05$ & $0.00 \mathrm{E}+00$ & 4.28E-03 \\
\hline
\end{tabular}

Table 2. Dose Report for RESRAD-Biota Level 3, at Water Canyon near State Road 501, on August 16, 2012 


\section{Terrestrial Biota}

At the other locations that received measurable storm water, the flow is ephemeral so we ran RESRADBiota for terrestrial animals and plants using the worst cases, i.e., the highest concentrations. The Level1 BCG report is listed in Tables 3, 4, and 5. The "Sum of Total Ratio" is 0.0191 , which is less than 1, and so demonstrates compliance with the DOE biota dose limits.

\section{Terrestrial BCG Report for Level 1}

Title: Worst cases

Sum of Total Ratio: 1.91E-02

Sum of Water Ratio: 1.91E-02

Sum of Soil Ratio: $0.00 \mathrm{E}+00$

Table 3. Level 1 Terrestrial BCG Report for the worst cases 


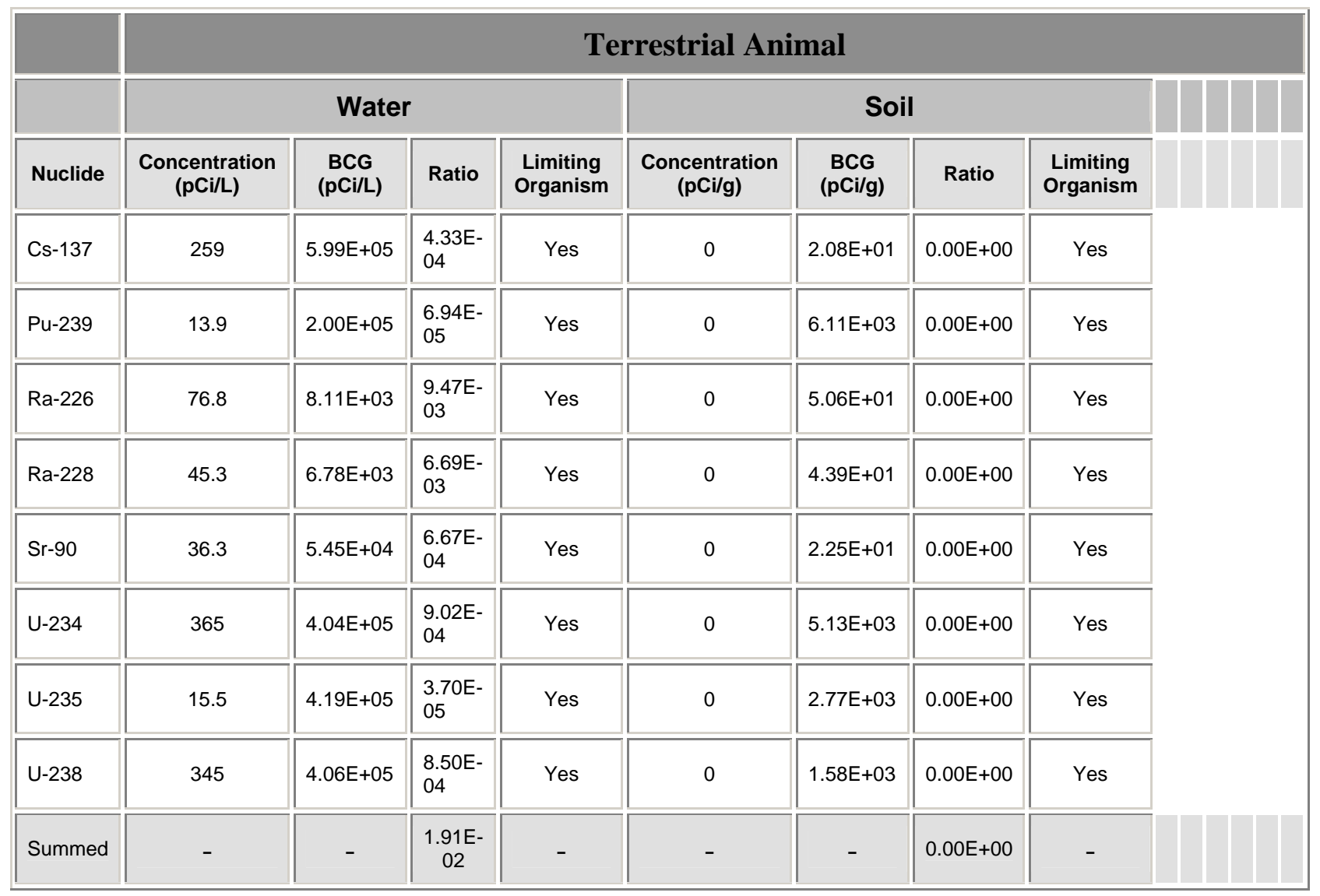

Table 4. Level 1 Terrestrial Animal BCG Report for the worst cases 


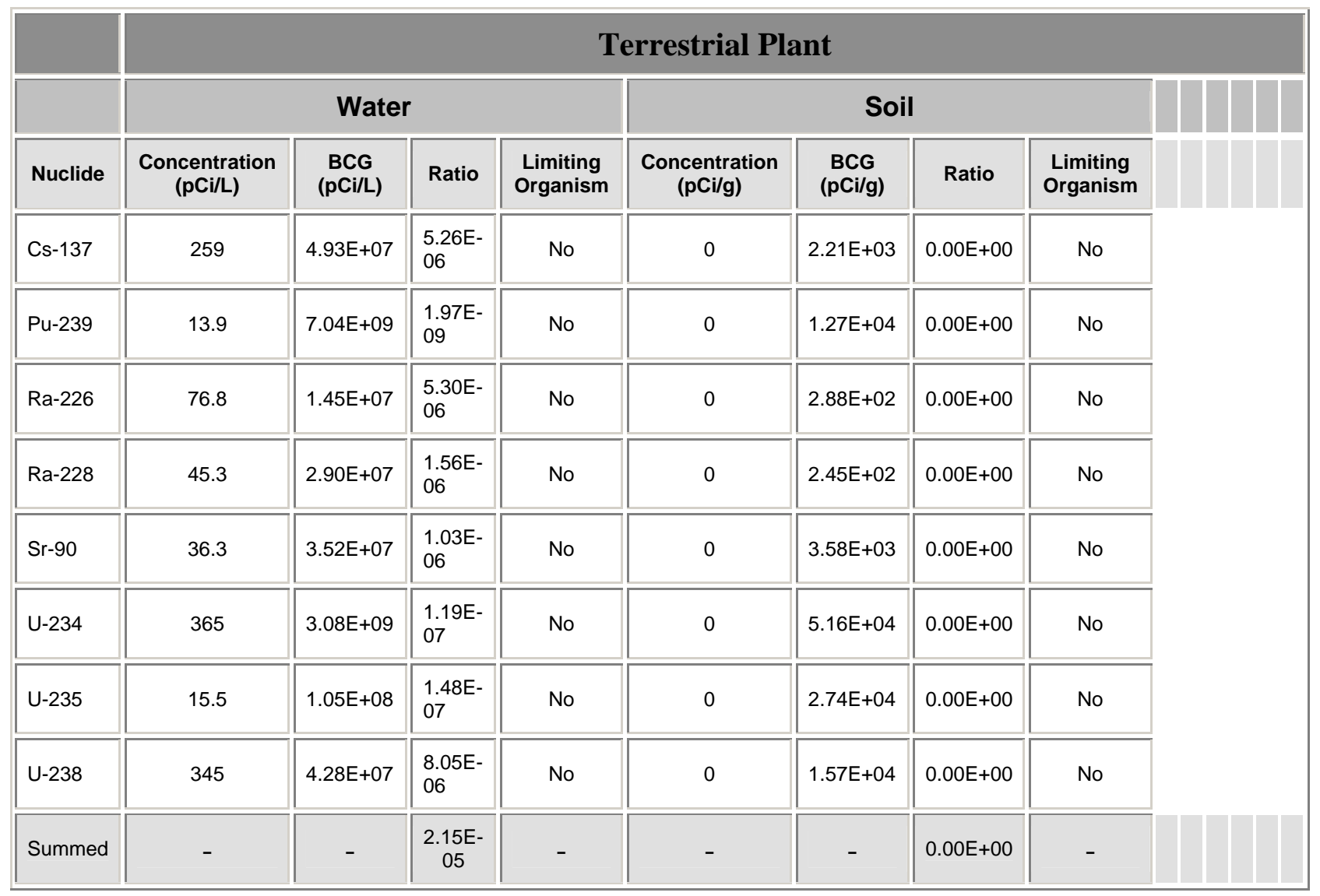

Table 5. Level 1 Terrestrial Plant BCG Report for the worst cases

\section{Summary of RESRAD Biota Results}

Tables 1 through 5 demonstrate compliance with DOE Order 458.1.

Most of the biota dose is from natural uranium in suspended sediment, so as suggested by DOE 2002, we discuss naturally-occurring radioactive material, NORM.

\section{NORM}

The perennial reaches of Water Canyon are near State Road 501, upstream of LANL influence, so the radioactive materials consists of NORM and global fallout. In this case, the DOE Standard, DOE 2002, asks for an assessment to consider possible impacts on biota from all NORM. Because the measurements were focused on compliance, they focused on radionuclides such as uranium-238 rather than its decay products such as radium-226. Before it is delivered to Los Alamos, LANL uranium is chemically refined to remove other chemical elements such as radium. However, because the sediment in Water canyon was NORM, it included radium-226 in secular equilibrium with uranium-238 and uranium-234. This was not measured but its presence is inferred. 


\section{Radium-226}

If we exclude radium-226, the level-3 assessment of aquatic dose (Table 2) decreases by a factor of 11.6 from $0.0185 \mathrm{rad} /$ day to an annual average of $0.0016 \mathrm{rad} /$ day. It is interesting to consider why radium226 makes such a large difference and whether this is realistic.

The reason is that radium is chemically similar to calcium so it bioaccumulates under some conditions, and the DOE standard assumes the worst-case conditions. This raises the question: are these conditions applicable to conditions near Los Alamos?

Radium is absorbed into living cells through the same biological process that absorbs calcium (IAEA 1984.) Most eukaryotes have some ability to discriminate between radium and calcium, so the absorption of radium depends on the concentration of calcium in the underlying media: soil, sediment, or water. The highest bioaccumulation occurs when the calcium concentrations are low $(<0.2 \%$, see Eisenbud and Gesell 1997) whereas near Los Alamos, calcium concentrations are high (1\%, see the LANL database and also USGS http://tin.er.usgs.gov/geochem/doc/averages/ca/usa.html ) so significant bioaccumulation is unlikely.

Strontium is also chemically similar to calcium, and strontium is also absorbed when calcium concentrations are low. This possibility was studied and reported in McNaughton et al. 2008a and Salazar 2006, with the conclusion that the plant-to-soil concentration ratio for strontium is approximately unity.

This raises the question of whether the radium in suspended sediment bioaccumulates in the same way as radium in solution. In the case of storm water within LANL, this question is academic. The question is more relevant for streams and rivers containing fish, such as the Rio Grande. It would be difficult to measure radium in the biota of Water Canyon because it would be difficult to collect enough biota mass to measure. It would be easier to measure radium in fish taken from the Rio Grande so we recommend that the radium concentration ratio should be measured in future years.

\section{Conclusions}

- The biota doses at LANL are well below the DOE limits.

- It would be interesting to measure radium-226 bioaccumulation factor in the Rio Grande or other rivers with high concentrations of natural uranium. 


\section{References}

DOE 2002: “A Graded Approach for Evaluating Radiation Dose to Aquatic and Terrestrial Biota," US Department of Energy Technical Standard 1153-2002 (August 2000). http://www.hss.doe.gov/nuclearsafety/ns/techstds/docs/standard/1153.htm

DOE 2011: "Radiation Protection of the Public and the Environment," US Department of Energy Order 458.1 (June 2011).

Eisenbud and Gesell 1997: "Environmental Radioactivity," ISBN 0-12-235154-1, Academic Press (1997).

IAEA 1984: "The Behaviour of Radium in Waterways and Aquifers," IAEA TECDOC-301, http://www-pub.iaea.org/MTCD/publications/PDF/te 301 web.pdf Vienna 1984

LANL 2009a: "Quality Assurance Project Plan for the Biota Dose Assessment," QAPP-05, R0 http://www.lanl.gov/environment/all/docs/qa wes/QAPP-05.pdf (2009).

LANL 2009b: "Calculating Dose to Non-human Biota," SOP-5243

http://www.lanl.gov/environment/all/docs/qa wes/SOP-5243.pdf (2009).

LANL 2012: “Environmental Report 2011,” LA-14461-ENV (2012).

LA-UR-90-4300 “Solid Waste Management Units Report,” 1990.

McNaughton 2005: "Biota Dose Assessment at LANL," Los Alamos National Laboratory document LA-UR05-4699 (2005).

McNaughton et al. 2008a: "Site-Representative Biota Concentration Guides at Los Alamos," Los Alamos National Laboratory document LA-UR-08-2783 (2008).

McNaughton 2008b: "Response to the Government Accountability Project, GAP," Los Alamos National Laboratory document LA-UR 08-07159 (2008).

Salazar 2006: S. Salazar, M. McNaughton, P.R. Fresquez, "Concentration Ratios for Cesium and Strontium in Produce Near Los Alamos," LA-14284 (2006). 